\title{
PRIOR KNEE OSTEOPOROSIS ASSOCIATING THE 10-YEAR CLINICAL OUTCOME OF TOTAL KNEE ARTHROPLASTY FOR RHEUMATOID ARTHRITIS: A RETROSPECTIVE STUDY
}

\author{
Yukiyoshi Oishi ${ }^{*}, \|$, Yuji Hirano*, Yukiharu Hasegawa ${ }^{\dagger}$, \\ Kenichi Yamauchi ${ }^{\ddagger}$, Yasuhide Kanayama ${ }^{\S}$ and Susumu Ota \\ *Department of Rheumatology, Toyohashi Municipal Hospital, Toyohashi, Japan \\ ${ }^{\dagger}$ Department of Orthopedic Surgery, Nagoya University Hospital, Nagoya, Japan \\ ${ }^{\ddagger}$ Department of Orthopedic Surgery, Toyohashi Municipal Hospital, \\ Toyohashi, Japan \\ ${ }^{\S}$ Department of Orthopedic Surgery, Toyota Kousei Hospital, Toyota, Japan \\ 'Department of Rehabilitation and Care, Seijoh University, Nagoya, Japan \\ "muku69oishi@gmail.com
}

Received 24 March 2017

Accepted 22 June 2017

Published 13 July 2017

\begin{abstract}
The aim of this retrospective study was to determine whether prior regional osteoporosis in the knee associates the 10-year outcome of total knee arthroplasty (TKA) in patients with rheumatoid arthritis (RA). About 63 knees of 45 RA patients underwent cruciate-retaining Deltafit TKA. Overall, long-term results of the RA disease activity were based on dual-energy X-ray absorptiometry (DXA) to evaluate osteoporosis; the Japanese Orthopedic Association (JOA) functional knee score, a disease activity score of 28 joints; and the neck large joint score 12 for joint destruction, which were investigated over 10 years. Multivariate analysis of factors affecting the JOA score at 10 years was performed. Factors affecting the JOA score at 10 years correlated with the DXA results at the distal femoral condyle,
\end{abstract}

Correspondence to: Dr. Yukiyoshi Oishi, Department of Rheumatology, Toyohashi Municipal Hospital, 50 Hachikennishi, Aotake-cho, Toyohashi, Aichi, Japan.

This is an Open Access article published by World Scientific Publishing Company. It is distributed under the terms of the Creative Commons Attribution 4.0 (CC-BY) License. Further distribution of this work is permitted, provided the original work is properly cited. 
patient age, and neck large joint score 12. Prior regional osteoporosis in the knee based on DXA negatively correlated the 10-year outcome of TKA in patients with RA.

Keywords: Bone mineral density; Dual-energy X-ray absorptiometry; Long-term outcome.

\section{INTRODUCTION}

The clinical survival of arthroplasty is affected by osteoporosis detected on dual-energy X-ray absorptiometry (DXA) as a standard measure of bone strength and quality. Some studies have examined post-operative periprosthetic bone mineral density in the hip over periods of more than 10 years. ${ }^{819}$ Studies have also been performed to examine post-operative periprosthetic bone mineral density in the knee in patients with $\mathrm{OA},{ }^{1,5}$ with some evaluating the relationship between the DXA results and middle or long-term outcomes of total knee arthroplasty (TKA) in OA, ${ }^{4,13,20}$ and others addressing the short-term relationship in patients with rheumatoid arthritis (RA). ${ }^{10,18}$ To our knowledge, however, there are no longterm outcome studies of TKA with DXA in patients with RA.

The pre-operative and post-operative bone mineral content affects the long-term revision rate after non-cement knee arthroplasty for OA. ${ }^{20}$ They also reported that DXA evaluation of five regions of interest (ROI) around the femoral component of the knee, particularly the lateral distal femoral condyle (FC), is useful for repeated measurement after TKA. ${ }^{20}$ The purpose of this retrospective study was to investigate the relationship between the DXA results of the FC and the 10-year outcome of TKA in patients with RA.

\section{PATIENTS AND METHODS}

Between 1993 and 2000, 103 knees underwent cruciate-retaining Deltafit TKA (Stryker Co.) for RA at the Toyohashi Municipal Hospital. A total of 63 knees of 45 patients ( 6 knees of 5 men and
57 knees of 40 women) with RA were followed up for 10 years after surgery. Mean age at the time of surgery was $57 \pm 11$ years, mean body weight was $49.0 \pm 9.0 \mathrm{~kg}$, mean height was $152 \pm 5.9 \mathrm{~cm}$, and mean body mass index was $21.0 \pm 3.3 \mathrm{~kg} / \mathrm{m}^{2}$. TKA was performed $14.2 \pm 7.6$ years after RA onset. At year 0, the RA stage of the hands was: stage $2(n=4)$, stage $3(n=32)$, and stage $4(n=27)$, but 10 years after the operation, the RA stage was: stage $2(n=0)$, stage 3 $(n=12)$, and stage $4(n=51)$. Two TKA methods were used: one was all-cement, and the other was a hybrid method in which a non-cement femoral component was applied. The hybrid method was used in 42 cases of mild regional osteoporosis (DXA: $0.56 \pm 0.14$ ), and all-cement fixation TKA was used in 21 cases of severe regional osteoporosis (DXA: $0.38 \pm 0.11$ ). All operations were completed within $2 \mathrm{~h}$ with one tourniquet that was not released during the operation and without allo-transfusion (i.e. no transfusion or auto-transfusion).

After surgery, the surgeon prescribed treatment with disease-modifying antirheumatic drugs and corticosteroid hormone. More than $75 \%$ of patients that underwent TKA were prescribed prednisolone (10 mg/day maximum, mean-dose $\sim 5 \mathrm{mg}$ / day). Prior to 2010, we did not administer bisphosphonate or biotic agents in our series.

The present study was approved by the Ethics committee of the Toyohashi Municipal Hospital.

\section{DXA}

Regional osteoporosis in the knee was examined by DXA (QDR 2000, Hollogic Co.) before TKA. 


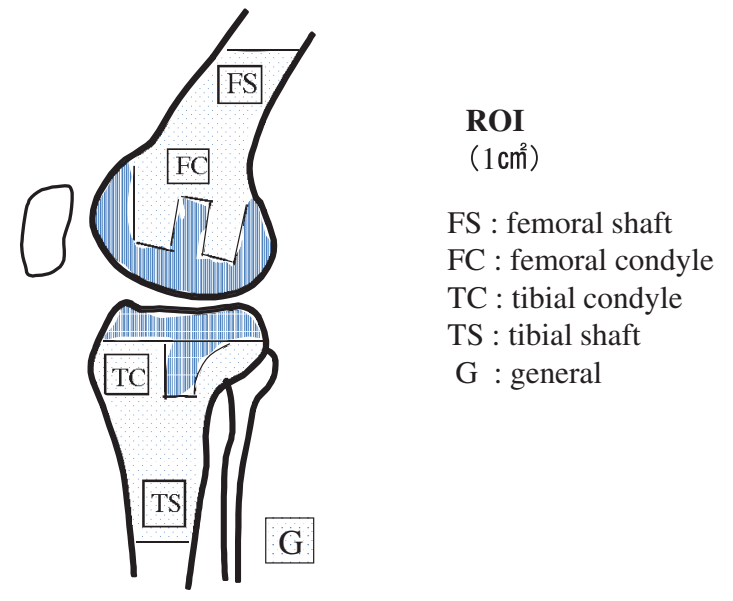

Fig. 1 DXA sites in the lateral view of the knee.

DXA was measured using the same equipment in this series and one radiologist assessed all measurements. As DXA of the FC at the lateral aspect of the knee is suitable for repeated measurement, ${ }^{13,20}$ we selected the DXA findings of the FC for the 10-year follow-up (Fig. 1).

\section{Japanese Orthopedic Association (JOA) Score}

Clinical assessment of the functional knee score was estimated according to the Criteria for Evaluating Rheumatoid Arthritis of the Knee proposed by the JOA. ${ }^{6,12}$ The JOA score comprises a maximum of 100 points categorized by: pain (40 points), range of motion (12 points), strength of quadriceps (20 points), ability to walk and extent (20 points), and ascending and descending stairs (8 points). A score of 100 points indicates the best function. The JOA score was assessed for both knee joints at the time of each TKA and 10 years after TKA. The JOA score is well established and its validity and response rates are reported in previous studies. ${ }^{7,12,16} \mathrm{We}$ applied the JOA scoring system to rate TKA outcome. A single rheumatologist (YO) evaluated the JOA score.

\section{Disease Activity Score (DAS) 28-Erythrocyte Sedimentation Rate (ESR)}

The DAS28-ESR (Category 3) ${ }^{21}$ was calculated from the patients' existing medical records. The three factors of the DAS28-ESR were number of tender joints, number of swollen joints, and ESR.

\section{Neck Large Joint Score 12 (NLJ Score 12)}

The NLJ score 12 is an X-ray assessment score we created and applied in Japan. ${ }^{11}$ A score of 12 means a patient has almost normal large joints without erosion. Before 2000, patients with RA exhibiting joint damage in their wrists and fingers underwent conventional disease-modifying antirheumatic drug therapy. Joint destruction in the large joints, however, severely affects the activities of daily living. We therefore assigned scores to most of the large joints in the body: bilateral shoulders, elbows, hips, knees, ankle joints and neck, with a score of 12 being the highest possible score. With regard to the cervical spine, we applied 1 point within a $5 \mathrm{~mm}$ atlanto-dental interval, ${ }^{2} 1$ point for a $13 \mathrm{~mm}$ vertical subluxation (Ranawat method), ${ }^{14}$ and 1 point for a $3 \mathrm{~mm}$ subaxial subluxation. The NLJ score 12 provides the historical results of joint destruction due to RA, thus giving a historical summary of the RA activity level, not a disease activity level at a single point in time. This is useful for evaluating other large joints that affect the results of TKA. The X-ray assessment for the NLJ score 12 was performed by a single rheumatologist (YO).

\section{Statistical Analysis}

To identify the best predictor of the JOA score at 10 years after TKA, we performed a stepwise multiple regression analysis. Only variables (independent values) that significantly correlated with the JOA score at 10 years after TKA were 
subsequently considered in the stepwise procedure. The TKA method type was included as an independent variable. Statistical analyses were performed using SPSS, version 17 (IBM Japan, Tokyo, Japan).

Only one infection occurred among 103 TKAs performed between 1993 and 2000. In this case, the patient became infected three years after TKA following a bout of pneumonia. None of the patients had a loose TKA after the first operation.

\section{RESULTS}

The mean DXA score of the FC before surgery was $0.50 \pm 0.13 \mathrm{~g} / \mathrm{cm}^{2}$. The mean JOA score was $42.4 \pm 14.1$ before surgery (at 0 years) and $80.4 \pm$ 10.9 at 10 years after TKA. The mean NLJ score 12 was $7.4 \pm 2.4$ before surgery and $5.6 \pm 2.8$ at 10 years after TKA. The mean JOA score at 10 years was $83 \pm 10$ after hybrid TKA and $76 \pm 12$ after all-cement TKA, but the difference in scores between groups was not statistically significant ( $p=0.058$, non-paired Student's $t$ test). The DAS 28-ESR did not correlate with the JOA score at 10 years (Table 1 ).

Of the independent variables evaluated, DXA (FC), patient age, and pre-TKA NLJ score 12 significantly correlated with the JOA score at 10 years after TKA (Table 2). Using a stepwise regression, DXA was entered in the regression

Table 1 Clinical outcomes at baseline and 10 years after TKA.

\begin{tabular}{lccr}
\hline & 0 years (baseline) & 10 years & $\boldsymbol{p}$ \\
\hline DXA of FC & $0.50 \pm 0.13$ & - & - \\
JOA score & $42.4 \pm 14.1$ & $80.4 \pm 10.9$ & $<0.001$ \\
DAS 28-ESR & $5.2 \pm 0.98$ & $4.8 \pm 1.2$ & 0.013 \\
NLJ score 12 & $7.4 \pm 2.4$ & $5.6 \pm 2.8$ & $<0.001$ \\
\hline
\end{tabular}

Note: DXA: dual-energy X-ray absorptionmetry; FC: femoral condyle; JOA: Japanese Orthopedic Association; DAS: Disease Activity Score 28-ESR; DAS 28-ESR; NLJ: Neck large joint.
Table 2 Factors affecting JOA score at 10 years. (Pearson's correlation coefficient)

\begin{tabular}{lcc}
\hline & Pearson correlation coefficient & $\boldsymbol{p}$ \\
\hline DXA of FC $(0 \mathrm{y})$ & 0.369 & 0.003 \\
Age $(0 \mathrm{y})$ & -0.361 & 0.004 \\
NLJ score $12(0 \mathrm{y})$ & 0.333 & 0.008 \\
JOA score $(0 \mathrm{y})$ & 0.237 & 0.061 \\
DAS 28-ESR $(0 \mathrm{Y})$ & -0.182 & 0.153 \\
\hline
\end{tabular}

Note: DXA: dual-energy X-ray absorptionmetry; FC: femoral condyle; JOA: Japanese Orthopedic Association; DAS: Disease Activity Score 28-ESR; DAS 28-ESR; NLJ: Neck large joint.

Table 3 Multivariate analysis affecting JOA score at 10 years.

\begin{tabular}{lrcrc}
\hline & $\boldsymbol{R}$ & Standardized B & \multicolumn{1}{c}{$\boldsymbol{t}$} & $\boldsymbol{p}$ \\
\hline DXA of FC (0 y) & 21.29 & 0.29 & 2.69 & 0.009 \\
Age & -0.37 & -0.36 & -3.34 & 0.001 \\
NLJ score 12 & 1.40 & 0.32 & 2.98 & 0.004 \\
\hline
\end{tabular}

Note: $R=0.58, R^{2}=0.34$, adjusted $R^{2}=0.31$

DXA: dual-energy X-ray absorptionmetry; FC: femoral condyle; NLJ: Neck large joint.

equation first and was found to be the largest predictor of JOA score variability at 10 years after TKA $\left(r^{2}=0.136, p=0.03\right.$; Table 3$)$. Patient age and pre-TKA NLJ score 12 were the next most consequential variables entered into the regression. Together, DXA, patient age, and pre-TKA NLJ score 12 accounted for $34 \%$ of the variance in the JOA score at 10 years after TKA $\left(r^{2}=0.34\right.$, $p<0.001$; Table 3). The DAS 28-ESR did not correlate with the JOA score at 10 years.

\section{DISCUSSION}

The multivariate analysis revealed that the significant factors of the 10-year clinical outcome of TKA in RA were the DXA results of the FC, patient age, and the pre-TKA NLJ score 12, with DXA findings being the highly correlated factor 
(Table 3). Osteoporosis in the knee is considered to affect both the middle and long-term clinical results of TKA. ${ }^{13,20}$ DXA is a good measurement for the early assessment of osteoporosis. ${ }^{5,17}$ In the present study, assessing the DXA before surgery was important because DXA of the FC decreases within 1 year after TKA in patients with RA as well as in patients with $\mathrm{OA}^{4,22}$ and influences the long-term outcome of TKA. Periprosthetic repeated DXA of the knee has been performed after TKA to check for loosening, but there are very few reports of the relationship between DXA and long-time outcome, and no reports of this relationship in patients with $\mathrm{RA}$.

The DXA findings of the FC and other factors correcting the JOA score at 10 years were examined (Table 1). Neither the DAS 28-ESR at preTKA, representing the inflammation of RA, nor the TKA procedure with or without cement correlated with the JOA score at 10 years.

We think flare-ups of high disease activity in RA over a long period of time lead to osteoporosis and joint destruction. Destruction of the knee and other large joints may lead to TKA and worsen the ability to perform activities of daily living. Finally, the functional knee score tended to decrease with age at 10 years after TKA. Activity in a diseased RA over a long time may cause a lower DXA level in the knee and prove to have even worse functional outcomes. Large joint destructions in the TKA group with 102 RA cases were two or three-fold more than those in the earlier RA group with 104 cases and the TKA group was functionally worse than in the earlier RA group. ${ }^{11}$ The knee functional scores were basically lower at 0 year and 10 years, and the patients with less daily activity may have basically a lower regional DXA level. Therefore, the DXA level of the knee at operation was correlated with 10 years TKA outcomes (Table 2).

Generally, all-cement TKA is indicated for patients with severe regional osteoporosis in the knee, and the non-cement or hybrid TKA ${ }^{1,3,15}$ is indicated for patients with no or only mild regional osteoporosis. The TKA methods used with or without cement - did not affect the JOA score at 10 years. A patient weighing $\sim 50 \mathrm{~kg}$ with a DXA score of over $0.56 \mathrm{~g} / \mathrm{cm}^{2}$ before surgery can be safely operated because we found no evidence of loosening at 10 years. This may be the first report of this criterion for patients with RA, and the DXA values are smaller than those in OA before TKA $\left(0.72 \pm 0.17 \mathrm{~g} / \mathrm{cm}^{2}[n=30]\right) .{ }^{10}$ Bisphosphonates are also reported to have protective effects on implant survival, ${ }^{9}$ but they were not administered in the present series.

One limitation of this study is that the JOA score may be associated with large joint dysfunction that is also assessed using the NLJ score 12. The second limitation is that only the femur was measured in this study. DXA measurements at other locations of the knee joint, e.g. the tibia, after TKA in patients with RA would be useful for comparison with DXA measurements at those locations after TKA in patients with OA because these measurements have been obtained at several locations of the femur and tibia in patients with OA. The third limitation is that we could not accurately follow the medications for osteoporosis (vitamin D, calcium) and RA (disease-modifying antirheumatic drugs, glucocorticoids) during the 10 years. Therefore, the present results should not be considered as medication effects.

In conclusion, it appears reasonable to state that regional osteoporosis prior to knee surgery has some negative effect on the 10-year clinical outcome of TKA in patients with RA.

\section{ACKNOWLEDGMENT}

We represent that this submission is original work, and is not under consideration for publication with any other journal. 


\section{References}

1. Abu-Rajab RB, Watson WS, Walker B, Roberts J, Gallacher SJ, Meek RM. Peri-prosthetic bone mineral density after total knee, arthroplasty. Cemented versus cementless fixation. J Bone Joint Surg Br 88(5): 606-613, 2006.

2. Hinek VC, Hopkins CE. Measurement of the atlantodental nterval in the adult. Am J Roentogenol 84: 945951, 1960.

3. Illgen R, Tueting J, Enright T, Schreibman K, McBeath A, Heiner J. Hybrid total knee arthroplasty. J Arthroplasty Supp. 19: 95-100, 2004.

4. Jaroma A, Soininvaara T, Kroger H. Periprosthetic tibial bone mineral density changes after total knee arthroplasty. Acta Orthop 87(3): 268-273, 2016.

5. Karbowski A, Schwitalle M, Eckardt A, Heine J. Periprosthetic bone remodeling after total knee arthroplasty: Early assessment by dual energy X-ray absorptiometry. Arch Orthop Trauma Surg 119(5-6): 324-326, 1999.

6. Koshino T, Okamoto R, Niwa S. The criteria for evaluating RA of the knee. (The Committee on Assessment Criteria for Knee Disease and Treatment of the Japanese Orthopedic Association) Kanehara Shuppan Co. May, 1994.

7. Lingard EA, Katz JN, Wright RJ, Wright EA, Sledge CB. Kinemax Outcomes Group (2001) Validity and responsiveness of the Knee Society Clinical Rating System in comparison with the SF-36 and WOMAC. J Bone Joint Surg Am 83-A: 1856-1864, 2001.

8. Merle C, Streit, MR, Volz, Pritsch M, Gotterbarm T, Aldinger PR. Bone remodeling around stable uncemented titanium stems during the second decade after total hip arthroplasty: A DXA study at 12 and 17 years. Osteoprosis Int 22(11): 2879-2786. doi: 10.1007/s00198010-1483-z Epub, 2010 Nov 23, 2011.

9. Namba RS, Inacio MCS, Cheetham TC, Dell RM, Paxton EW, Khatod MX. Lower total knee arthroplasty revision risk associated with bisphosphonate use, even in patients with normal bone density. J Arthroplasty 31: 537-541, 2016.

10. Oishi Y, Kanayama Y, Kachi H. Bone mineral density in the knee before and after the fifty TKA operations in RA females. J Chubu Rheum Assoc 33(1): 24-25, 2002 (in Japanese).

11. Oishi Y, Yamauchi K, Sato H, Hasegawa S, Kobayakawa T. General large joint destruction in 102 RA patients followed up for 5 to 15 years after TKA. Jpn J Joint Dis 28(2): 243-249, 2009 (in Japanese).
12. Okuda M, Omokawa S, Okahashi K, Akahane M, Tanaka Y. Validity and reliability of the Japanese Orthopaedic Association score for osteoarthritic knees. J Orthop Sci 17: 750-756, 2012.

13. Petersen MM, Olsen C, Lauritzen JB, Lund B. Changes in bone mineral density of the distal femur following uncemented total knee arthroplasty. J Arthroplasty 10(1): 7-11, 1995.

14. Ranawat CS, O'Leary P, Pellicci $P$, Tsairis $P$, Marchisello $\mathrm{P}$, Dorr L. Cervical spine fusion in rheumatoid arthritis. J Bone Joint Surg 61-A: 1003-1010, 1979.

15. Rorabeck $\mathrm{CH}$. Total knee replacement: Should it be cemented or hybrid? Can J Surg 42: 21-61, 1999.

16. Sasaki E, Tsuda E, Yamamoto Y, Meada S, Otsuka H, Ishibashi Y. Relationship between patient-based outcome score and conventional objective outcome scales in post-operative total knee arthroplasty patients. Int Orthop (SICOT) 38: 373-378, 2014.

17. Soininvaara TA, Kröger $H$, Jurvelin JS, Miettinen $H$, Suomalainen O, Alhava E. Measurement of bone density around total knee arthroplasty using fan-beam dual energy X-ray absorptiometry. Calcif Tissue lnt 67(3): 267-272, 2000.

18. Spittlehouse AJ, Getty CJ, Eastell R. Measurement of bone mineral density by dual-energy X-ray absorptiometry around an uncemented knee prosthesis. J Arthroplasty 14(8): 957-963, 1999.

19. Tapaninen T, Kroger H, Venesmaa P. Periprosthetic BMD after cemented and uncemented total hip arthroplasty: a10-year follow-up study. J Orthop Sci 20: 657662, 2015.

20. Therbo M, Petersen MM, Schroder HM, Nielsen PK, Zerahn B, Lund B. The precision and influence of rotation for measurements of bone mineral density of the distal femur following total knee arthroplasty: A methodological study using DEXA. Acta Orthop Scand 74(6): 677-682, 2003.

21. van der Heiji DM, va'nt Hof MA, van Riel PLCM, Theunisse LAM, Lubberts EW, van Leeuwen MA. Judging disease activity in clinical practice in rheumatoid arthritis: First step in the development of a disease activity score. Ann Rheum Dis 49: 916-920, 1990.

22. van Jonbergen $\mathrm{HP}$, Koster $\mathrm{K}$, Labey L, Innocent $\mathrm{B}$, van Kampen A. Distal femoral bone mineral density decreases following patellofemoral arthroplasty; 1-year follow-up study of 14 patients. BMC Musculoskelet Disord 11: 74, 2010. doi: 10.1186/1471-2474-11-74. 